See discussions, stats, and author profiles for this publication at: https://www.researchgate.net/publication/282791521

\title{
Why Is Later Age at Retirement Beneficial for Cognition? Results from a French Population-based Study
}

Article in The Journal of Nutrition Health and Aging · October 2015

DOI: 10.1007/s12603-015-0599-4

CITATIONS

23

7 authors, including:

Catherine Grotz

University of South Florida and University of Lige

20 PUBLICATIONS 197 CITATIONS

SEE PROFILE

Stéphane Adam

University of Liège

167 PUBLICATIONS 2,434 CITATIONS

SEE PROFILE

Some of the authors of this publication are also working on these related projects:

Non-Pharmacological Interventions (NPIs) Taxonomy View project

Project Predictive Modeling in Psychiatry and Neurology View project
READS

312

Yaakov Stern

Columbia University Vagalos College of Physicians and Surgeons 1,022 PUBLICATIONS 83,198 CITATIONS

SEE PROFILE 


\title{
WHY IS LATER AGE AT RETIREMENT BENEFICIAL FOR COGNITION? RESULTS FROM A FRENCH POPULATION-BASED STUDY
}

\author{
C. GROTZ1, C. MEILLON² ${ }^{2}$ H. AMIEVA², Y. STERN ${ }^{3}$, J.-F. DARTIGUES ${ }^{2}$, S. ADAM $^{1}$, L. LETENNEUR $^{2}$

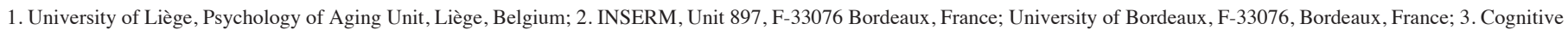 \\ Neuroscience Division, Department of Neurology and Taub Institute, Columbia University College of Physicians and Surgeons, New York, NY, USA. Corresponding author: Catherine \\ Grotz, Unité de Psychologie de la Sénescence, University of Liège, Traverse des Architectes (B63c) - Sart Tilman, B-4000 Liège, Belgium, Phone number: + 32436628 46; \\ e-mail: cgrotz@ulg.ac.be.
}

\begin{abstract}
Objective: To determine whether and how age at retirement influences the risk of dementia. The association between the age at retirement, the number of working years and the risk of dementia was evaluated over 12 years of follow-up. Design: A prospective population-based study. Setting: Three-City cohort, a French population-based study of community-dwelling individuals aged 65 to 95 . Participants: The sample consisted of 1,658 non-demented participants at baseline. Measurements: All participants were evaluated at home at the initial visit and at two years interval for a period of 12 years. An active research of dementia was conducted at each follow-up; all suspected cases were analysed by an independent committee of neurologists. Information regarding retirement age and number of working years was collected at baseline using a structured questionnaire. Results: The multivariate Cox model, including both the age at retirement and the number of working years and adjusted for potential confounders, revealed that the risk of dementia was independently associated with the age at retirement $(\mathrm{p}=0.022)$ but not with the number of working years $(\mathrm{p}=0.296)$. Conclusion: Although our results are in accordance with previous studies (i.e., older age at retirement is associated with decreased risk of dementia), it provides additional information regarding the possible explanation for such results. Given that a longer working life did not reduce the risk of dementia, the age at retirement cannot be considered as a new factor of cognitive reserve but rather seems to be a psycho-social vulnerability factor. Further evidence is necessary to identify work and retirement related factors that influence the association between the age at retirement and the risk of dementia.
\end{abstract}

Key words: Aging, dementia, age at retirement, cognitive functioning, cognitive reserve.

\section{Introduction}

Most people spend a tremendous portion of their lives at work, which provides a great source of social interaction and stimulating activities. Leaving the work setting is therefore a major life course transition that causes substantial changes in one's life and hence may affect cognitive functioning of older adults. Indeed, several studies (1-4) have reported a negative impact of retirement on cognitive function. Likewise, three recent studies addressed this issue in the context of pathological aging and reported that deferred retirement is associated with both reduced risk of developing dementia $(5,6)$ and delayed onset of Alzheimer's disease (AD) (7). The possibility that later age at retirement decreases age-related cognitive deficits or the risk of dementia has major clinical but also policy implications. Greater understanding of the mechanisms involved in the association between retirement age and cognition takes on increased importance.

Two hypotheses can be put forward to explain why later age of retirement could be beneficial for cognitive health of older adults. First, later departure from the workforce could reflect a longer time spent at work and therefore would be associated with greater cognitive reserve, as previously suggested. The longer people stay professionally active (i.e., greater years of work), the more it provides a reserve that act to compensate for the effects of age-related cognitive impairment and pathology.

Received May 20, 2015

Accepted for publication July 1, 2015
The second assumption could be that the act of leaving the workforce carries with it substantial environmental, cognitive and social changes for individuals. In that sense, the ongoing demands of working life (e.g., schedule constraints, social network, cognitive activities, management of private life) help maintain cognitive function. According to that view, later age of retirement implies a longer maintenance of high level of functioning.

In view of the above, the aim of this study is to better understand why later retirement age would reduce the risk of developing dementia. This question was investigated through the use of data from the Three City Study (3C), a large French prospective cohort of community-dwelling older subjects. We first explored whether deferred retirement is associated with reduced risk of dementia at the 12-year follow-up of the cohort. Second, we hypothesized that if later retirement protects against dementia by increasing cognitive reserve then each additional year of work should also provide a reserve that would reduce the risk of developing dementia.

\section{Methods}

\section{Study design and sample}

Participants were part of the $3 \mathrm{C}$, a prospective epidemiologic study of vascular risk factors for dementia initiated in 19992000. The methodology has been previously described (8). 
WHY IS LATER AGE AT RETIREMENT BENEFICIAL FOR COGNITION?

The research procedures were reviewed and approved by the ethical committee of the University Hospital of KremlinBicêtre (Paris, France) according to the principles embodied in the Declaration of Helsinki. All participants provided informed consent. Briefly, 9,294 community dwellers, initially noninstitutionalized, aged $\geq 65$ years were randomly selected from the electoral rolls in three French Cities: Bordeaux $(\mathrm{n}=$ $2,104)$, Dijon $(n=4,931)$, Montpellier $(n=2,259)$. Subjects were evaluated at home at the initial visit and at two years interval for a period of 12 years. At each visit, a psychologist administered a questionnaire on sociodemographic data and a comprehensive neuropsychological assessment.

\section{Dementia cases}

A standardized three-step procedure was used to diagnose cases of dementia (8). First, screening was based on a comprehensive neuropsychological examination by trained neuropsychologists. Data on activities of daily living, severity of cognitive disorders, and, where possible, magnetic resonance images or computed tomography scans were collected. Second, individuals who met dementia criteria were seen at home by a neurologist who confirmed or rejected the diagnosis. Finally, all available information was reviewed by an independent panel of specialized neurologists who applied the following criteria for each etiological category: NINCDS-ADRDA criteria for AD (9), NINDS-AIREN criteria for vascular dementia (10), standardized clinical criteria for fronto-temporal dementia (11), Lewy body disease (12), and a history of Parkinson disease for Parkinson dementia.

For this study, to avoid the issue of possible reverse causality between retirement and incident dementia (i.e., retirement as a consequence of prior cognitive impairment), individuals who were diagnosed within 10 years after retirement were excluded from the analyses. Since the prodromal phase of AD has been shown to last more than a decade, only individuals who retired for more than 10 years were taken into consideration (13). This procedure has also been used in another study (6).

\section{Explanatory variables and covariables}

Information regarding the age at retirement and the number of years spent at work was collected during the inclusion visit. Such information was ascertained using a structured questionnaire. The age at retirement refers to the age at which participants retired from paid work. In the analysis, the age at retirement was categorized as follows: (1) aged $\leq 55$ years old, (2) aged between ]55; 60[ years old, (3) 60 years old (the reference category), (4) aged between 160; 65] years and (5) aged $>65$ years old. Regarding the number of working years, the participant was asked to indicate how many years did he/she spend working in their professional career.

Several variables were considered as potential confounding factors and controlled for in the statistical analyses. The sociodemographic variables included gender, educational level (defined as a three-level variable: no diploma, primary diploma, secondary diploma or more), occupation (defined as blue/white collar) and socioeconomic status (current monthly household income) categorized as follows: $(1)<760$ euros, (2) between 760 and 1500 euros, (3) between 1500 and 2300 euros, (4) $>2300$ euros, (5) unknown. The presence of cardiovascular risk factors was taken into account as follows: diabetes $(\geq$ $6.1 \mathrm{mmol} / \mathrm{L}$ or taking oral diabetic medications or insulin), hypercholesterolemia ( $\geq 6.2 \mathrm{mmol} / \mathrm{L}$ ), hypertension (systolic blood pressure $\geq 160 \mathrm{mmHg}$, diastolic blood pressure $\geq 95$ $\mathrm{mmHg}$ ) and personal history of stroke. Apolipoprotein $\mathrm{E}$ (ApoE) $\varepsilon 4$ allele (genotyping of ApoE was performed at Lille Genopole, France) was also noted. Finally, the presence of depressive symptomatology was assessed using the French version of the Center for Epidemiological Studies Depression Scale (CES-D, self-report questionnaire composed of 20 items) in which participants were asked how often they experienced certain feelings during the previous week. Participants were considered as having depressive symptomatology if they were treated for antidepressant or had a score above the cut-off score at the CES-D (validated French cut-off scores of 17 for men and 23 for women) (14).

\section{Data analysis}

To estimate the risk of future dementia associated with both the age at retirement and the number of working years, multivariate Cox proportional hazards model with delayed entry, in which the time-scale was the individual's age, was conducted. Indeed, in order to avoid potential bias, it is recommended to use age as time scale in age-dependent diseases rather than time-on-study (15).

The time used was the age of diagnosis of dementia or the age at the last follow-up visit for those who were not diagnosed. The multivariate model controlled for the following confounding factors: gender, educational level, occupation, socioeconomic status, depression, cardiovascular risk factors (i.e., diabetes, hypercholesterolemia, hypertension and personal history of stroke) and ApoE genotype. The SAS version 9.3 (SAS Institute, Inc., Cary, North Carolina) was used for all analyses.

\section{Results}

\section{Sample Characteristics}

This study only considered the 2,104 subjects from the center of Bordeaux and excluded the following participants: 77 prevalent cases of dementia at baseline, 205 housewives, 282 subjects with missing data for the age at retirement and 339 for the number of working years. Of the remaining 1,658 retired subjects, 40 subjects diagnosed within 10 years after retirement were excluded from the sample. Thus, the final study sample included 1,618 subjects. After 12 years follow-up, 253 incident dementia cases (15.6\%) were reported.

Table 1 displays baseline characteristics of the sample. Participants were more often women, more educated and a 


\section{THE JOURNAL OF NUTRITION, HEALTH \& AGING@}

large percentage retired at the age of $60(43.5 \%)$, which is the modal age of retirement. About $5 \%$ of the participants retired after age 65 and more than one third have worked for more than 40 years.

Table 1

Characteristics of the study sample. 3C Study, $n=1,618$

\begin{tabular}{|c|c|c|}
\hline Characteristics & Unit & $\mathbf{n}(\%)$ \\
\hline Age at baseline & Years, mean (SD) & $74.4(4.9)$ \\
\hline Gender & Women & $916(56.6)$ \\
\hline \multicolumn{3}{|l|}{ Education (1 MV) } \\
\hline & 1- Without diploma & $187(11.7)$ \\
\hline & 2- Primary diploma & $386(23.9)$ \\
\hline & 3- >primary diploma & $1044(64.6)$ \\
\hline Occupation (13 MV) & Blue collar & $493(30.7)$ \\
\hline \multicolumn{3}{|l|}{ Income (16 MV) } \\
\hline & $<750$ euros & $140(8.7)$ \\
\hline & $750-1500$ euros & $542(33.8)$ \\
\hline & $1500-2300$ euros & $393(24.5)$ \\
\hline & $\geq 2300$ euros & $427(26.7)$ \\
\hline & Unknown & $100(6.2)$ \\
\hline \multicolumn{3}{|l|}{ Age at retirement } \\
\hline & $\leq 55$ years & $417(25.8)$ \\
\hline & ] $55 ; 60[$ & $287(17.7)$ \\
\hline & 60 & $437(27.0)$ \\
\hline & ] $60 ; 65]$ & $395(24.4)$ \\
\hline & $>65$ & $82(5.1)$ \\
\hline \multicolumn{3}{|l|}{ Number of working years } \\
\hline & $<40$ & $901(55.7)$ \\
\hline & 40 & $164(10.1)$ \\
\hline & $>40$ & $553(34.2)$ \\
\hline Diabetes & & $258(16.0)$ \\
\hline Hypercholesterolemia & & $878(58.0)$ \\
\hline Hypertension (1 MV) & & $1063(65.7)$ \\
\hline Apolipoprotein E $\varepsilon 4$ (176 MV) & & $256(17.8)$ \\
\hline History of stroke (5 MV) & & $44(2.7)$ \\
\hline Depression (18 MV) & & $120(7.5)$ \\
\hline MMSE score (15 MV) & mean $(\mathrm{SD})$ & $27.4(2.0)$ \\
\hline
\end{tabular}

Association between both the age at retirement, the number of working years and the risk of dementia

The results of the multivariate model (Table 2), including both the age at retirement and the number of working years, showed that after controlling for potential confounding factors (gender, educational level, occupation, socioeconomic status, depression, diabetes, hypercholesterolemia, hypertension, history of stroke and ApoE genotype), the age at retirement was significantly associated with the risk of dementia $(\mathrm{p}=0.022)$. The different categories of age at retirement indicated a trend towards a reduced risk of dementia with increasing age at retirement. The risk of dementia was respectively $28 \%$ and $43 \%$ lower in individuals who retired between $60-65$ years and over the age of 65 than in individuals who retired at 60 years old ( $\mathrm{HR}=0.72, \mathrm{p}=\mathrm{p}=0.081 ; \mathrm{HR}=0.57, \mathrm{p}=0.100$, respectively). Conversely, controlling for the same confounding factors and the age of retirement, the number of years individuals spent working was not associated with the risk of dementia $(p=0.296)$. Noted, a sensitivity analysis showed that when considering in the analyses individuals who were diagnosed within 10 years after retirement the results remained unchanged.

\section{Discussion}

The main purpose of this paper was to better understand the repeated observation of a beneficial effect of later age of retirement on cognitive function of older adults (1-4) and on the risk of dementia (5-7). To do so, we evaluated the association between the retirement age, the number of working years and the risk of subsequent dementia in a population-based study sample of 1,618 older adults followed prospectively during a 12-year period.

Our results indicated that the age at retirement was associated with the risk of dementia, which is consistent with previous findings (5-7). Specifically, we found a trend towards a reduced risk of dementia with increasing age at retirement. Such results were obtained after controlling for several confounding factors (i.e., gender, educational level, occupation, socioeconomic status, depression, several cardiovascular risk factors and ApoE genotype) and also by taking into account the number of years that people spent at work. These results might suggest that later retirement contributes to cognitive reserve. However, if a later age at retirement reflects a longer working life and consequently a higher reserve, the risk of dementia should also be related to the number of working years. In contrast, our results showed that for an equal age at retirement, the number of working years was not related to the risk of dementia. Therefore, the age at retirement cannot be considered as a proxy of cognitive reserve. One potential explanation for our findings is that it is not the number of years spent at work per se, but rather the transition period from work to retirement that impacts on subsequent dementia. Indeed, the working life not only involves schedule constraints but also provides to individuals a great source of social support (16) and a sense of self-efficacy (17). It also requires allocating a great amount of cognitive resources to both professional and daily life activities. Leaving the workforce is therefore a major life event that implies that individuals have to relinquish an environment 
WHY IS LATER AGE AT RETIREMENT BENEFICIAL FOR COGNITION?

Table 2

Subsequent risk of dementia after 12 years of follow-up according to age at retirement and the number of working years. 3C Study, $\mathrm{n}=1,395$

\begin{tabular}{|c|c|c|c|c|}
\hline & & \multicolumn{3}{|c|}{ Multivariate analyses* } \\
\hline & & HR & $95 \% \mathrm{CI}$ & $p$ value \\
\hline \multirow[t]{6}{*}{ Age at retirement } & & & & 0.022 \\
\hline & $\leq 55$ years & 1.19 & 0.81 to 1.76 & 0.383 \\
\hline & ] $55 ; 60[$ & 0.65 & 0.41 to 1.03 & 0.066 \\
\hline & 60 & 1 & & \\
\hline & ]60; 65] & 0.72 & 0.49 to 1.04 & 0.081 \\
\hline & $>65$ & 0.57 & 0.30 to 1.11 & 0.100 \\
\hline \multirow[t]{4}{*}{ Number of working years } & & & & 0.296 \\
\hline & $<40$ & 1.08 & 0.62 to 1.89 & 0.796 \\
\hline & 40 & 1 & & \\
\hline & $>40$ & 1.38 & 0.78 to 2.42 & 0.270 \\
\hline
\end{tabular}

$\mathrm{HR}=$ hazard ratio; $\mathrm{CI}=$ confidence interval

in which he/she embedded and requires a change of pace. This rupture may certainly generate a period of vulnerability among newly retired people. This hypothesis is supported by a study (2) that examined the association between retirement and cognitive functioning using data from the longitudinal Health and Retirement Study (14,710 American aged 51 to 75 at baseline). They reported that cognitive performances slowly decreased with time but interestingly, they also showed a significant drop in cognitive scores from 62 to 63 years old. No physiological reason can explain such abrupt cognitive change at those particular ages, but they do correspond to the minimum age at which social security benefits can be claimed and also to the peak of retirement wave in the United States. This suggests that there is a rupture at the time of retirement that affects the cognitive functioning of older adults.

Regarding the retirement transition assumed to cause a rupture in cognitive functioning, our study provides additional information since it indicates that the later it occurs, the lower is the risk of dementia. As previously mentioned, the demands of the working life and especially occupational setting, certainly help individuals to maintain a high level of functioning. Therefore, one possible explanation to this finding is that individuals who retired at a later age were able to continue to function at a higher level for a longer time.

In addition, due to societal perceptions of aging, we can hypothesize that retiring after the age of 65 does not have the same consequences as retiring before the age of 65 . The transition from the working life to retirement entails a major change in social roles and status (18), which is negatively perceived by many western countries (19). Our society views older adults and retirees as those people who have nothing to offer to society and who are lacking in productivity $(19,20)$. There is evidence that these negative attitudes adversely affect cognitive performance of older adults (21-23). Nevertheless, the possibility that later retirees may more easily accept the changes in roles and status can be postulated. Being retired above the age of 65 years old is a normal and socially accepted phenomenon. Thus, the retirement transition process is certainly eased by the fact that it is perceived as "normal" by society and that most of one's friends and colleagues of the same age share the same social status.

Other psychological factors could also explain why the retirement adjustment process may be smoother among late retirees. People who retire at a later age probably have additional time to prepare adequately for retirement (i.e., planning post retirement activities, gradual disinvestment from work). In addition, the personal choice to remain in the workforce above the societally normative retirement age, gives them a sense of control over their retirement decision. It is a well-known phenomenon that perceived control over the departure from the workforce is crucial to retirement adjustment (e.g., perceived quality of life, health) $(24,25)$ whereas forced or involuntary departure from the workforce has detrimental effects on health (26) and well-being (including depression and life satisfaction) $(24,27-29)$. It is important to point out that numerous factors may influence the retirement adjustment quality. Therefore, further researches should seek to determine the psychosocial factors that may explain why some individuals are more or less at risk to develop dementia.

The transition from work to retirement is a complex process - one that comprises numerous factors that may influence the retirement adjustment quality and that may explain why individuals are more or less at risk to develop dementia. One interesting theory that could be applied when studying the effect of retirement on health and cognitive functioning is the life course perspective (30-32). This theory emphasizes that 


\section{THE JOURNAL OF NUTRITION, HEALTH \& AGINGC}

the quality of retirement adjustment depends upon the various resources and contexts surrounding retirement transitions (e.g., control over the departure from the workforce, marital quality, income and health status). Although the life course perspective provides a general framework for understanding retirement adjustment, it does not consider different ages at retirement. Thus, a question of interest would be to determine whether the adjustment to retirement is different according to the age at retirement, and therefore would differently impact subsequent cognitive functioning. Further research should therefore evaluate this theoretical model and seek to identify factors that play a role in the association between retirement and cognitive functioning of older adults. A better understanding of these psychosocial factors would lead to the development of health policies that are more tailored to the professional and psychological specific context of each individual.

The strengths and the limitations of this study should also be discussed. The present study has several advantages such as its size, the population-based design, the long-term follow up and the control for numerous potential confounders. However, despite these advantages this study has also some limitations. One limitation is the lack of information regarding participants before retirement since they were not in the cohort at that time. In particular, the cognitive functioning of participants before retirement and right after the departure of the workforce is unknown. A second limitation is that no detailed information regarding the reason for departure from the workforce, the leisure activities before and after retirement, the regime of timework and the nature of the work were gathered. Furthermore, while the distinction blue and white collar has been used elsewhere (33), a detailed description of the complexity of the work would have help to refine these results and should be the subject of future studies. In addition, these findings must be viewed in the socio-political context of France and therefore cannot be generalized to the entire world population. In France, retirement is a legal requirement for all citizens and the statutory retirement age was 60 years old at the time of enrollment in the study (except for independent professions where there is no mandatory retirement age). This explains that the 60 years of age was the modal class (i.e., the majority of subjects retired at that age). However, despite this specific context our present results do not support that working longer is beneficial for the health of seniors. It would be interesting that further studies make a comparison between European Countries with different mandatory age of retirement and also with countries with no age restrictions for retirement such as the United States or Canada.

In conclusion, our results show that even though deferred retirement is associated with reduced risk of dementia, a longer working life is not associated with such reduced risk. Therefore, our study provides evidence that the age at retirement does not directly contribute to cognitive reserve but rather should be considered as a factor of cognitive and psychosocial vulnerability when it occurs too early. In the context of our aging societies, a better understanding of the factors making the retirement transition a period of psycho-social vulnerability would be essential for the development of future senior health policies.

Acknowledgments: The 3C study was conducted under a partnership agreement between the "Institut National de la Santé et de la Recherche Médicale" (INSERM), the "Institut de Santé Publique et Développement of the Victor Segalen-Bordeaux2 University", and "Sanofi-Aventis". The Fondation pour la Recherche Médicale funded the preparation and initiation of the study. The 3C study is also supported by the Caisse Nationale Maladie des Travailleurs Salariés, Direction Générale de la Santé, Mutuelle Générale de l'Education Nationale, Institut of the Longévité, Regional Councils of Aquitaine and Bourgogne, Fondation de France , and Ministry of Research-INSERM Program "Cohortes et Collections de données biologiques". Catherine Grotz is supported by the Fund for Scientific Research (F. R. S. - FNRS), Belgium (www.frs-fnrs.be).

Author contributions: C. Grotz contributed to the study concept and design, data interpretation and drafted the manuscript. C. Meillon was involved in data analysis and revised the results. JF. Dartigues contributed to data collection and critically revised the manuscript for important intellectual content. H. Amieva, S. Adam and L. Letenneur contributed to the study concept and design, and critically revised the manuscript for important intellectual content. L. Letenneur was also involved in data analysis. Y. Stern critically revised the manuscript for important intellectual content. All authors approved the final version of the manuscript. Authors had full access to all of the data in the study and L. Letenneur, H. Amieva and JF. Dartigues take responsibility for the integrity of the data and the accuracy of the data analysis.

Ethics approval: The 3C was approved by the ethical committee of the University Hospital of Kremlin-Bicêtre (Paris, France).

Conflict of interests: none.

Submission declaration: All authors have contributed to the work and agree with the contents of the manuscript. The authors ascertain that the manuscript is not under consideration for publication elsewhere, its publication is approved by all authors and by the responsible authorities where the work has been carried out. If accepted, it will not be published elsewhere including electronically in the same form, in English or in any other language, without the written consent of the copyright-holder.

Sponsor's role: None.

Funding: The Fondation pour la Recherche Médicale funded the preparation and initiation of the study. The $3 \mathrm{C}$ study is also supported by the Caisse Nationale Maladie des Travailleurs Salariés, Direction Générale de la Santé, Mutuelle Générale de l'Education Nationale, Institut of the Longévité, Regional Councils of Aquitaine and Bourgogne, Fondation de France, and Ministry of Research-INSERM Program "Cohortes et Collections de données biologiques". The funding organizations played no role in the design and conduct of the study, in the collection, management, analysis, and interpretation of the data, or in preparation, review, or approval of the manuscript.

\section{References}

1. Adam S, Bonsang E, Grotz C, Perelman S. Occupational activity and cognitive reserve: implications in terms of prevention of cognitive aging and Alzheimer's disease. Clin Interv Aging 2013;8: 377-390. doi:10.2147/cia.s39921.

2. Bonsang E, Adam S, Perelman S. Does retirement affect cognitive functioning? J Health Econ 2012;31: 490-501. doi:10.1016/j.jhealeco.2012.03.005.

3. Mazzonna F, Peracchi F. Ageing, cognitive abilities and retirement. Eur Econ Rev 2012;56: 691-710.

4. Rohwedder S, Willis RJ. Mental retirement. J Econ Perspect 2010;24: 119-138. doi:10.1257/jep.24.1.119.

5. Dufouil C, Pereira E, Chêne G, Glymour MM, Alpérovitch A, et al. Older age at retirement is associated with decreased risk of dementia. Eur J Epidemiol 2014;29: 353-361. doi :10.1007/s10654-014-9906-3.

6. Grotz C, Letenneur L, Bonsang E, Amieva H, Meillon C, Quertemont E, et al Retirement Age and the Age of Onset of Alzheimer's Disease: Results from the ICTUS Study. PLoS ONE 2015;10(2): e0115056. doi:10.1371/journal.pone.0115056.

7. Lupton MK, Stahl D, Archer N, Foy C, Poppe M, et al. Education, occupation and retirement age effects on the age of onset of Alzheimer's disease. Int J Geriatr Psychiatry 2010;25: 30-36. doi:10.1002/gps.2294.

8. Group TCS. Vascular factors and risk of dementia: design of the Three-City Study and baseline characteristics of the study population. Neuroepidemiology 2003;22: 316-325.

9. McKhann G, Drachman D, Folstein M, Katzman R, Price D, et al. Clinical diagnosis of Alzheimer's disease: report of the NINCDS-ADRDA Work Group under the 


\section{WHY IS LATER AGE AT RETIREMENT BENEFICIAL FOR COGNITION?}

auspices of Department of Health and Human Services Task Force on Alzheimer's Disease. Neurology 1984;34: 939-944.

10. Román GC, Tatemichi TK, Erkinjuntti T, Cummings J, Masdeu J, et al. Vascular dementia Diagnostic criteria for research studies: Report of the NINDS-AIREN International Workshop*. Neurology 1993;43: 250-260.

11. Englund B, Brun A, Gustafson L, Passant U, Mann D, et al. Clinical and neuropathological criteria for frontotemporal dementia. J Neurol Neurosurg Psychiatry 1994;57: 416-418.

12. McKeith IG, Galasko D, Kosaka K, Perry EK, Dickson DW, et al. Consensus guidelines for the clinical and pathologic diagnosis of dementia with Lewy bodies (DLB): Report of the consortium on DLB international workshop. Neurology 1996;47: 1113-1124.

13. Amieva H, Le Goff M, Millet X, Orgogozo JM, Peres K, et al. Prodromal Alzheimer's disease: Successive emergence of the clinical symptoms. Ann Neurol 2008;64: 492-498.

14. Fuhrer R, Antonucci TC, Gagnon M, Dartigues JF, Barberger-Gateau P, et al. Depressive symptomatology and cognitive functioning: an epidemiological survey in an elderly community sample in France. Psychol Med 1992;22: 159-172.

15. Thiebaut AC, Benichou J. Choice of time-scale in Cox's model analysis of epidemiologic cohort data: A simulation study. Stat Med 2004;23: 3803-3820.

16. Szinovacz ME. Contexts and pathways: Retirement as institution, process, and experience. In: Adams GA, Beehr TA (ed). Retirement: Reasons, processes, and results. New-York, pp. 2003;6-52.

17. Rowe JW, Kahn RL. Successful aging. Pantheon Books, New York, 1998.

18. George LK. Sociological perspectives on life transitions. Annu rev sociol 1993;19: 353-373. doi:10.1146/annurev.so.19.080193.002033.

19. Price CA. Women and retirement: Relinquishing professional identity. J Aging Stud 2000;14: 81-101. doi:10.1016/S0890-4065(00)80017-1.

20. Nelson TD. Ageism: Prejudice against our feared future self. J Soc Issues 2005;61: 207-221.

21. Abrams D, Eller A, Bryant J. An age apart: the effects of intergenerational contact and stereotype threat on performance and intergroup bias. Psychol Aging 2006;21: 691-702.

22. Horton S, Baker J, Pearce G, Deakin JM. On the malleability of performance implications for seniors. J Appl Gerontol 2008;27: 446-465. doi:10.1177/0733464808315291.

23. Levy B. Stereotype embodiment a psychosocial approach to aging. Curr Dir Psychol Sci 2009;18: 332-336. doi:10.1111/j.1467-8721.2009.01662.x.

24. Hershey DA, Henkens K. Impact of different types of retirement transitions on perceived satisfaction with life. The Gerontologist, 2013. doi:10.1093/geront/gnt006.

25. Henkens K, van Solinge H, Gallo WT. Effects of retirement voluntariness on change in smoking, drinking and physical activity among Dutch older workers. Eur J Public Health 2008;18: 644-649. doi:10.1093/eurpub/ckn095.

26. Van Solinge H. Health Change in Retirement A Longitudinal Study among Older Workers in the Netherlands. Res Aging 2007;29: 225-256. doi:10.1177/0164027506298223.

27. Hyde M, Hanson LM, Chungkham HS, Leineweber C, Westerlund $\mathrm{H}$. The impact of involuntary exit from employment in later life on the risk of major depression and being prescribed anti-depressant medication. Aging Ment Health 2015;19: 381-389. doi:10.1080/13607863.2014.927821

28. Calvo E, Haverstick K, Sass SA. Gradual retirement, sense of control, and retirees' happiness. Res Aging 2009;31: 112-135. doi:10.1177/0164027508324704.

29. Brand JE, Levy BR, Gallo WT. Effects of layoffs and plant closings on subsequent depression among older workers. Res Aging 2008;30: 701-721. doi:10.1177/0164027508322574.

30. Elder GH. The life course paradigm: Social change and individual development In: Moen P, Elder G. H., K Luscher (ed). Examining lives in contexts: Perspectives on the ecology of human development Washington DC: American Psychological Association, 1995;. pp 101-139.

31. Elder GH, Johnson MK. The life course and aging: Challenges, lessons, and new directions. In: Settersten RA (ed). Invitation to the life course: Toward new understandings of later life. New York NY: Baywood publishing company 2003, pp 49-81.

32. Wang M, Henkens K, van Solinge H. Retirement adjustment: A review of theoretical and empirical advancements. Am Psychol 2011;66: 204-213

33. Coe NB, von Gaudecker HM, Lindeboom M, Maurer J. The effect of retirement on cognitive functioning. Health economics 2012;21: 913-927. 